\title{
Qualitative and Quantitative Study on the Suppository of Penyankang
}

\author{
Linli Xia ${ }^{1}$, Xiehe Wang ${ }^{1}$, Congying Wang², Ying Song ${ }^{3 *}$ \\ ${ }^{1}$ Chengdu University of Traditional Chinese Medicine (TCM), Chengdu, China \\ ${ }^{2}$ Huanghe Science and Technology College, Zhengzhou, China \\ ${ }^{3}$ Affiliated Hospital of Chengdu University of Traditional Chinese Medicine, Chengdu, China \\ Email: 1293553776@qq.com, songying624@163.com
}

Received 18 July 2016; accepted 9 August 2016; published 12 August 2016

Copyright (C) 2016 by authors and OALib.

This work is licensed under the Creative Commons Attribution International License (CC BY).

http://creativecommons.org/licenses/by/4.0/

(c) (i) Open Access

\begin{abstract}
Objective: To establish the quality standard for Penyankang Suppository. Method: Thin Layer Identification (TLC) was used for the qualitative identification of Caulis Sargentodoxae, Radix Salviae Miltiorrhizae, Rhizoma Corydalis and Rhizom Sparganii. High performance liquid chromatography (HPLC) was used to determine the contents of salvianolic acid B and tetrahydropalmatine. Results: Thin Layer Identification (TLC) spots were clear and well separated without interference in the negative reference. The compounds showed a good linearity in a determination range. Conclusion: The method is simple, reliable and accurate with good precision. It can be used for the quality control of Penyankang Suppository.
\end{abstract}

\section{Keywords}

Penyankang Suppository, TLC, Salvianolic Acid B, Tetrahydropalmatine

Subject Areas: Pharmacology

\section{Introduction}

Penyankangshuan Affiliated Hospital of Chengdu University of traditional Chinese medicine Professor Shao binwei years of clinical experience of enema modified agent and agent, composed of six kinds of Chinese Medicine: Radix Salviae Miltiorrhizae, Rhizoma Corydalis (vinegar), Caulis Sargentodoxae, dandelion, dahurian Patrinia herb and Rhizoma Sparganii, with the effect of qingrejiedu, invigorate the circulation of qi and disease elimination fights. Clinical use for chronic pelvic inflammatory disease, endometriosis was caused by the lower abdomen and lumbar sacral pain, pelvic mass, dysmenorrhea, infertility, etc. [1] in order to use the convenience of patients, in our previous research on the preparation process of the modified suppository [2]. In order to ef-

*Corresponding author. 
fectively control the quality of the product to ensure clinical efficacy, combined with previous process parameters, the experiment established party Sargentgloryvine Stem, Caulis Sargentodoxae, Radix Salviae Miltiorrhizae, Rhizoma Corydalis and Rhizoma Sparganii TLC method; and the preparation in the main active ingredients of salvianolic acid B and tetrahydropalmatine were HTLC and quantitative analysis, to establish the quality standard of penyankangshuan.

Radix Salviae Miltiorrhizae for labiatae plants Salvia miltiorrhiza Salvia miltiorrhiza Bge dry root and rhizome. Rhizoma Corydalis (vinegar) for the poppy plant yanhusuo Corydalis yanhusuo W.T. Wang dry tuber, processing with vinegar. Caulis Sargentodoxae is also known as red cane for lardizabalaceae big blood vine plants Sargentodoxacuneata (Oliv.) Rehd. Et Wils. Dry stem. Dandelion is compositae dandelion Taraxacummongolicum Hand.-Mazz., alkaline dandelion Taraxacumborealisinense Kitam. Or all belong to several kinds of plant dry grass. Dahurian Patrinia Herband as a failure sauce genus chrysanthemum sauce Patrinia scabiosaefolia he, or white flowers with sauce Patriniavillosa Juss. The dry grass, Rhizoma Sparganii as black triangular secco plant black triangular Sparganium stoloniferum Buch.-Ham. Dry tubers.

\section{Instruments and Reagents}

HP1100 High performance liquid chromatograph (Hewlett-Packard Company), BP211D analytical balance (type 1/100000, sartorius Ag), JA2003 electronic balance (Shanghai Jingke balance), SHB-type III circulating water type multipurpose vacuum pump (Zhengzhou the Great Wall Branch Industry \& Trade Co., Ltd.). The filtration membrane is Nylon 66 (The aperture is $0.45 \mu \mathrm{l}$ ).

Reference herb of Caulis Sargentodoxae (Chengdu neautus traditional Chinese medicine company, Batch number: 121353-200401), reference herb of Rhizoma Corydalis (Chengdu neautus traditional Chinese medicine company, Batch number: 120928-201007),reference herb of Rhizoma Sparganii (Chengdu neautus traditional Chinese medicine company, Batch number: 121251-201103),The sample of Penyankangshuan (Self made in the hospital, the batch number is respectively 140301, 140302, 140303).

Salvianolic acid B (111562-201212, 95.4\%), Salvianic acid A sodium (110855-201311), tetrahydropalmatine (110726-201112, 99.6\%), Salidroside (110818-201206), All purchased from the China Pharmaceutical and Biological Products Institute.

Methanol and acetonitrile were pure, and water was distilled water, and the other reagents were all analyzed.

\section{Methods}

\subsection{Thin Layer Identification}

Caulis Sargentodoxae thin layer identification [3] [4] According to take samples of 4 g, add 50 ml methanol, water bath ultrasonic processing $50^{\circ} \mathrm{C}$ for 30 minutes, put the cold, filtration, the filtrate to dry residue with methanol $2 \mathrm{ml}$ to dissolve, as the test solution. Another Caulis Sargentodoxae were controlled $1 \mathrm{~g}$, with the legal system into a controlled medicine solution. Other prescription proportion according to take in addition to the Caulis Sargentodoxae the rest 5 herbs, according to the preparation technology of the preparation of Caulis Sargentodoxae deficiency cany negative samples, prepared with the negative contrast solution. Another take Salidroside, add methanol made each $1 \mathrm{ml}$ contains $0.5 \mathrm{mg}$ reference substance solution. Samples, referenceherb, negative sample $10 \mu \mathrm{l}$ and salidroside $3 \mu \mathrm{l}$ point in the same silica $\mathrm{G}$ thin layer plate, with methylene chloridemethanol-acetone-water (12:3:1:1) as developing agent, and taken out, dried, iodine cylinder in 3 minutes, remove and waved plate on the adsorption of iodine, sunlight to examine. To result in the chromatogram of the test, control and reference substance flecks on the corresponding position, show the same color spots, and negative without interference (see Figure 1).

Radix Salviae Miltiorrhizae thin layer identification [5] [6] Take samples $0.5 \mathrm{~g}$ said, $20 \mathrm{ml}$ of water, water bath $50^{\circ} \mathrm{C}$ dissolve, placed in the refrigerator $2 \mathrm{~h}$, remove and filtration, the filtrate to add a certain amount of dilute hydrochloric acid $\mathrm{pH}$ value is 2 - 3, filtration, the filtrate 2 times were extracted with ethyl acetate, every time $20 \mathrm{ml}$, merger acetic ester liquid, dry, residue and ethyl acetate $1 \mathrm{ml}$ to dissolve, as the test solution. Prescription proportion according to take the rest 5 ingredients except Radix Salviae Miltiorrhizae, according to the preparation of negative samples preparation process, preparation of salvia miltiorrhiza negative contrast solution according to the above method. The other Salvianic acid A sodium amount of sodium with reference substance, and ethyl acetate from each $1 \mathrm{ml}$ contains $0.5 \mathrm{mg}$ of reference substance solution. From the above three kinds of 


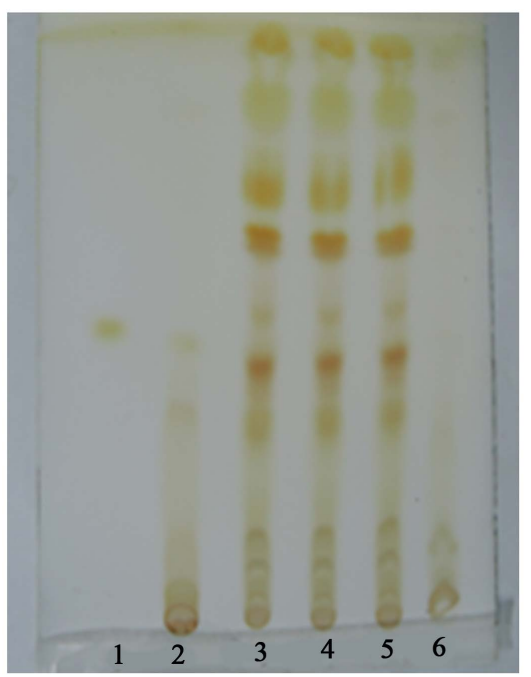

Figure 1. TLC Chromatogram of Caulis Sargentodoxae. 1. Salidroside; 2. Reference herb of Caulis Sargentodoxae; 3-5. Samples; 6. Negative sample.

solution each respectively $5 \mu \mathrm{l}$, point to the same silica $\mathrm{G}$ thin layer plate, in chloroform-acetone-formic acid (25:10:4) as developing agent, unfolds, remove and dry ammonia steam smoked $3 \mathrm{~min}$, remove and place $0.5 \mathrm{~h}$, $365 \mathrm{~nm}$ uv lamp under review. Results in the chromatogram of the test, and reference substance spots on the corresponding position, show the same color spots, and negative without interference (see Figure 2).

Rhizoma Corydalisthin layer identification [7] According to take samples of $2 \mathrm{~g}$, add $50 \mathrm{ml}$ of methanol, water bath $50^{\circ} \mathrm{C}$ ultrasonic treatment for 20 minutes, placed in the refrigerator $2 \mathrm{~h}$, remove and filtration, the filtrate to dry residue water $10 \mathrm{ml}$ dissolved, add ammonia test solution to alkaline, ether was used to extract 3 times, each time $10 \mathrm{ml}$, merge ether liquid, dry, residual methanol $1 \mathrm{ml}$ to dissolve, as the test solution. The prescription proportion according to take in addition to outside the rest 5 herbs, refluxing according to the preparation technology of the preparation of the negative samples, prepared with the negative contrast solution. Another reference herb of Rhizoma Corydalis $1 \mathrm{~g}$, refluxing with legal system into a controlled medicine solution. Another take Tetrahydropalmatine control, add methanol made each $1 \mathrm{ml}$ contains $0.5 \mathrm{mg}$ of reference substance solution. Respectively from the reference substance and contrast medicinal materials solution $2 \mu \mathrm{l}$, samples and the negative control solution $5 \mu \mathrm{l}$ respectively, point to the same silica $\mathrm{G}$ thin layer plate, with toluene-acetone (9:2) as developing agent, and taken out, dried, iodine cylinder in about 3 minutes, remove and waved plate on the adsorption of iodine, examined under a $365 \mathrm{~nm}$ uv lamp. To result in the chromatogram of the test, control and reference substance spots on the corresponding position, show the same color spots, and negative without interference (see Figure 3).

Rhizoma Sparganiithin layer identification [8] Said take $10 \mathrm{~g}$ sample, add $50 \mathrm{ml}$ ethanol, water bath ultrasonic processing $50^{\circ} \mathrm{C}$ for 30 minutes, put the cold, filtration, the filtrate to dry, residual ethanol $2 \mathrm{ml}$ to dissolve, as the test solution. The prescription proportion according to take the rest 5 ingredients, except Rhizoma Sparganii according to the preparation technology of the preparation of the negative samples, according to the above method preparation of negative control solution. The other reference herb of Rhizoma Sparganii $2 \mathrm{~g}$, plus $30 \mathrm{ml}$ of ethanol, heating reflux for 1 hour, filtration, the filtrate to dry residue plus $2 \mathrm{ml}$ dissolved with ethanol, a control solution of herbs. Respectively from the above three kinds of solution $10 \mu \mathrm{l}$, point to the same silica $\mathrm{G}$ thin layer plate, with petroleum ether $\left(60^{\circ} \mathrm{C}-90^{\circ} \mathrm{C}\right)$-ethyl acetate (4:1) as developing agent,, remove and dry, can be examined under a $365 \mathrm{~nm}$ uvlamp. To result in the chromatogram of the test, control spots on the corresponding position, show the same color spots, and negative without interference (see Figure 4).

\subsection{The Quantitative Determination}

\subsubsection{Salvianolic Acid B Content Determination [9]}

The chromatographic conditions: The C18 chromatographic column (Comatex ODS, $4.6 \mathrm{~mm} \times 250 \mathrm{~mm}, 5 \mu \mathrm{m}$ ); Detection wavelength $286 \mathrm{~nm}$; Mobile phase of methanol-acetonitrile-1\% formic acid (20:14:66); The velocity is $1.0 \mathrm{ml} / \mathrm{min}$; Sample quantity for $10 \mu \mathrm{l}$; Column temperature $30^{\circ} \mathrm{C}$. 


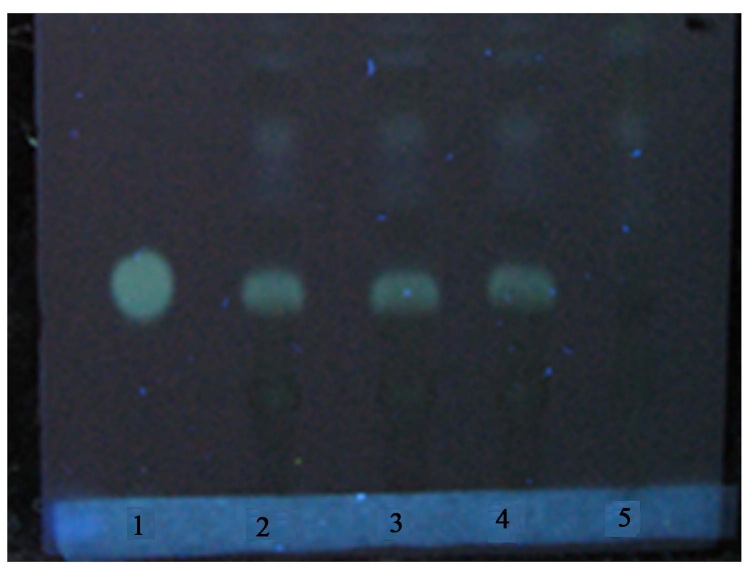

Figure 2. TLC Chromatogram of Radix Salviae Miltiorrhizae (UV365 nm). 1. Salvianic acid A sodium; 2-4. Samples; 5 . Negative sample.

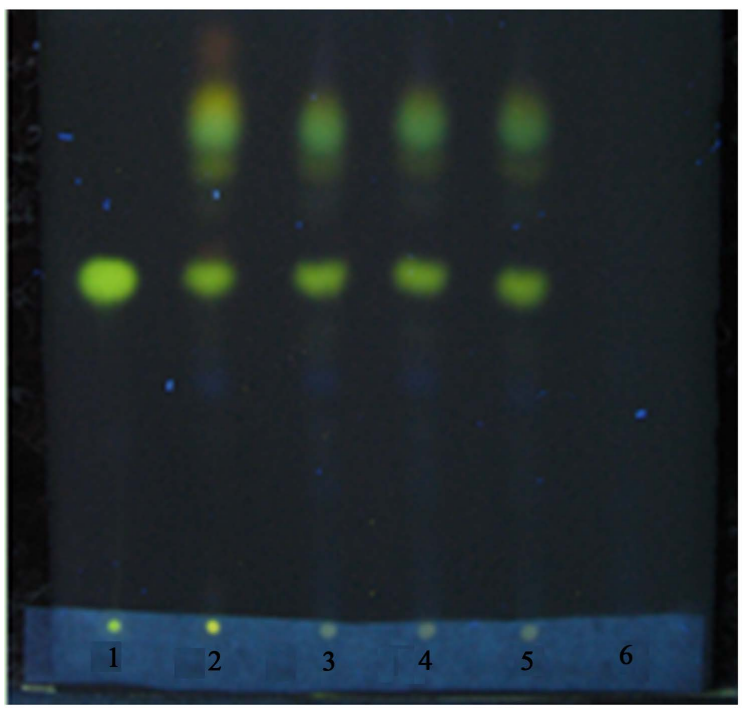

Figure 3. TLC Chromatogram of Rhizoma Corydalis (UV365 nm). 1. Tetrahydropalmatine control; 2. Reference herb of Rhizoma Corydalis; 3-5. Samples; 6 . Negative sample.

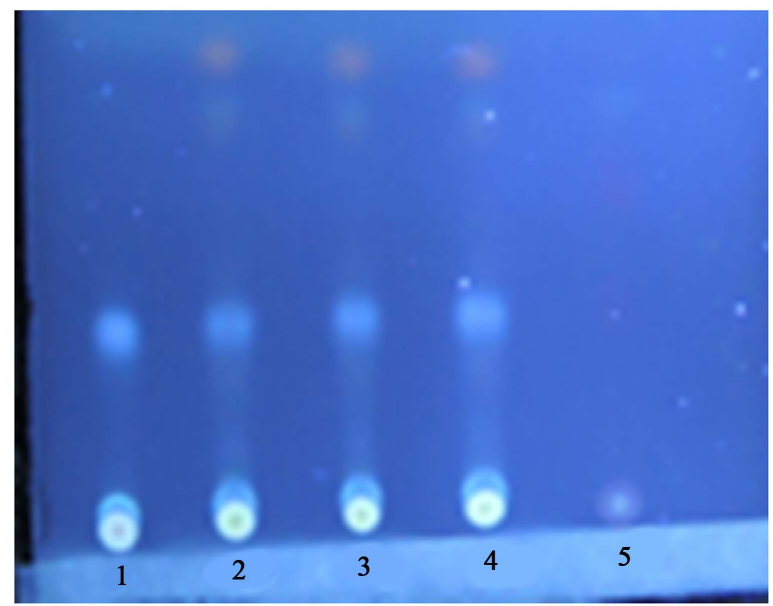

Figure 4. TLC Chromatogram of Rhizoma Sparganii (UV365 nm). 1. Reference herb of Rhizoma Sparganii; 2-4. Samples; 5 . Negative sample. 
The preparation of the reference substance solution: Precisely weigh the right amount of Salvianolic acid B, plus $75 \%$ methanol made each $1 \mathrm{ml}$ solution containing $0.352 \mathrm{mg}$.

The preparation of test sample solution: Precision according to fixed sample $1 \mathrm{~g}$ in $50 \mathrm{ml}$ volumetric flask and $25 \%$ methanol water bath ultrasonic processing $20 \mathrm{~min}$, take out $4{ }^{\circ} \mathrm{C}$ refrigerator put $4 \mathrm{~h}$, the filter for a quick.

Negative for preparation of test sample solution: Samples from lack of Radix Salviae Miltiorrhizae negative, negative according to the preparation of test sample solution method, the reference solution.

The linear range: Precision respectively from Salvianolic acid B1, 3, 5, 10, 15, $20 \mu \mathrm{l}$, chromatographic conditions according to the above analysis, the peak area as the ordinate, sample quantity as abscissa drawing standard curve, calculate the regression equation $\mathrm{Y}=676.84 \mathrm{X}-13.212, \mathrm{r}^{2}=1.0000$. The results showed that the Salvianolic acid B sample concentration within the scope of 0.3358 to $6.716 \mu \mathrm{g}$ good linear with peak area.

The specific test: Precision from Salvianolic acid B control products, test samples, negative control solution, chromatographic conditions according to the above analysis, the results of test samples of chromatographic peak of chromatographic peak of Salvianolic acid Band adjacent to the baseline separation of theoretical plate number calculated by Salvianolic acid B peak is not less than 2000, degree of separation $>1.5$, negative without interference (see Figures 5-7).

The precision test: Precision from the reference substance solution $3 \mathrm{ml}, 10 \mathrm{ml}$ volumetric flask to add the capacity, the methanol chromatographic conditions, according to the sample determination of six times in a row, the Salvianolic acid B average peak area is 825.2 , RSD was $0.852 \%$, the results show that the precision is good.

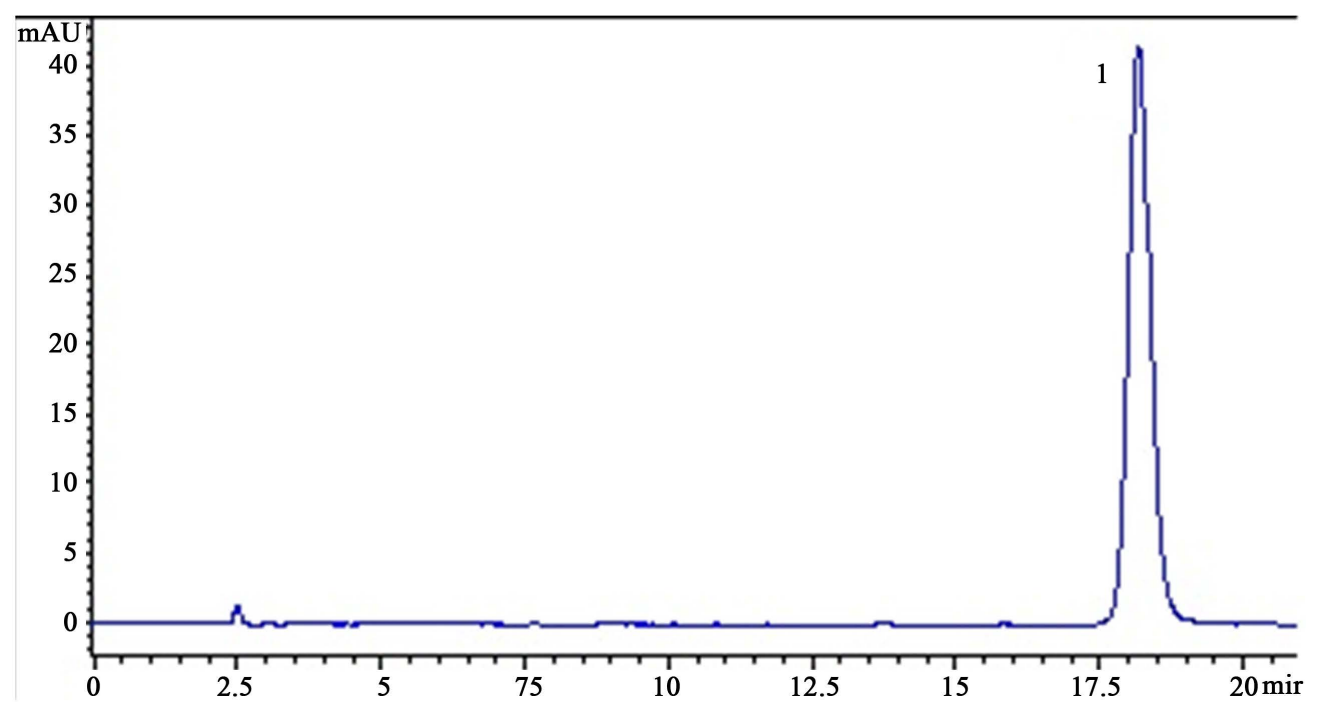

Figure 5. Salvianolic acid Bchromatogram. 1. The wave peak of Salvianolic acid B.

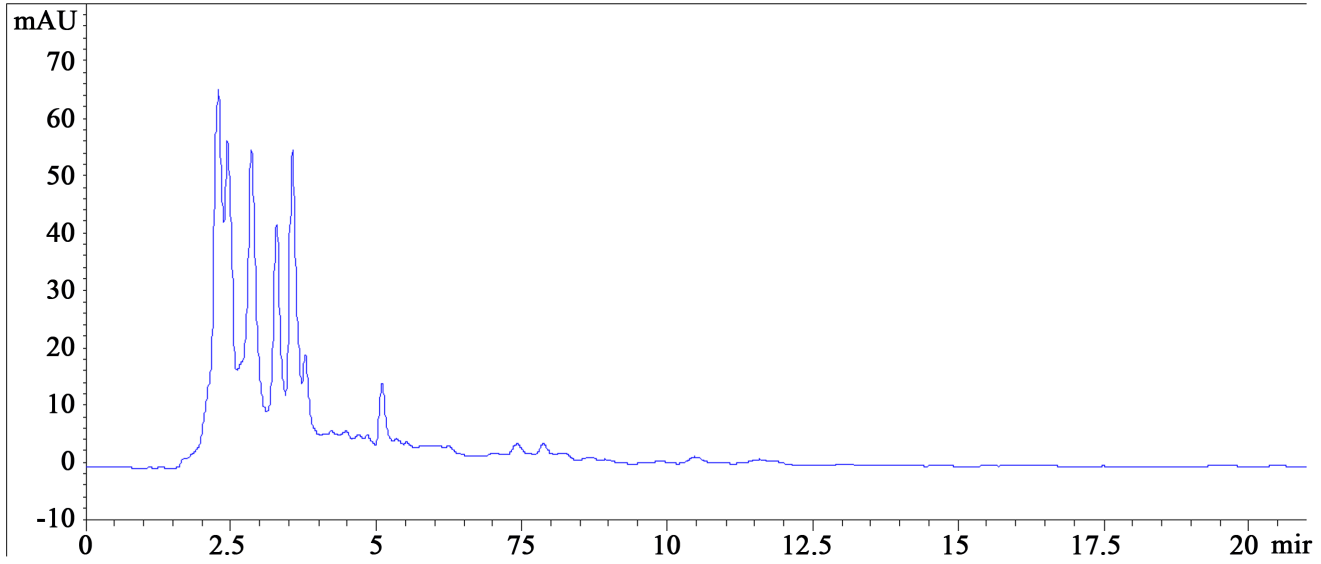

Figure 6. The suppository of Penyankang lack of Radix Salviae Miltiorrhizae negative chromatograms. 


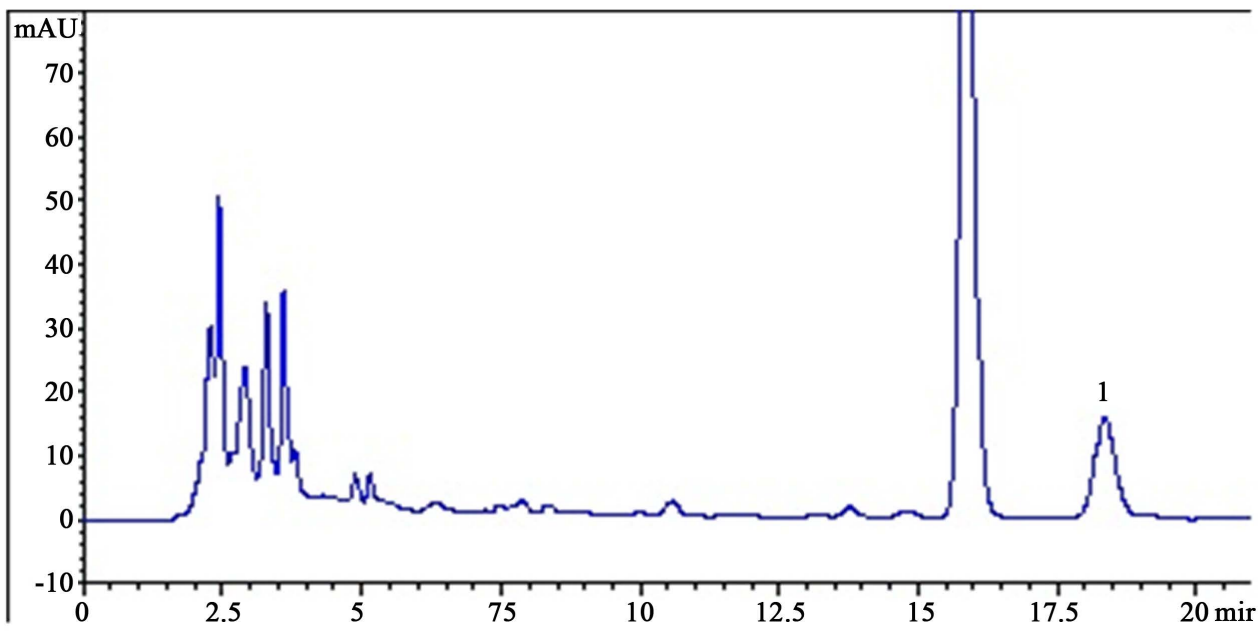

Figure 7. The suppository of Penyankang sample chromatograms. 1. The wave peak of Salvianolic acid B.

The stability test: Precision greatly from the solution at $0,2,4,6,8,10 \mathrm{~h}$ sample, record each peak area of sample, sample results average peak area is 391.3, RSD was $1.89 \%$, the results show that within $10 \mathrm{~h}$ of test sample solution stability.

The repeatability test: Precision according to samples of Penyankang Suppository 6 copies, according to the preparation of test sample solution preparation, according to the above sample chromatographic conditions, the determination of the peak area, content and relative standard deviation calculation, the result was that the Salvianolic acid B content average was $2.748 \mathrm{mg} \cdot \mathrm{g}^{-1}$, RSD was $0.756 \%$, the result showed that the method has good repeatability.

The sample recovery rate test: Recycling method with adding samples, samples from known levels (2.748 $\mathrm{mg} \cdot \mathrm{g}^{-1}$ ) of about $0.5 \mathrm{~g}$, precision said, a total of $6,50 \mathrm{ml}$ volumetric flask, respectively, to join the preparation of the reference substance solution $5 \mathrm{ml}(1.345 \mathrm{mg})$, and solvent dilution and constant volume to scale. According to the preparation of test sample solution, according to the determination of the chromatographic conditions, calculation of recovery, the Salvianolic acid B, the average recovery was $98.24 \%$, RSD was $1.92 \%$, showed that the method of sample recovery rate, better accuracy.

The determination of the sample: Three batch of pilot samples, 2 per batch, according to the preparation methods of the preparation of sample solution of test sample solution, according to the determination of the chromatographic conditions, calculate the content of the Salvianolic acid B. 3 batches of samples determination results to an average of $5.877 \mathrm{mg} /$ grain, according to the 2010 edition of "Chinese pharmacopoeia” a "Radix Salviae Miltiorrhizae" under the relevant provisions and stability test requirements, and considering the mass production have a range of fluctuation in the content, tentative products containing Salvianolic acid B, total amount not less than $2.2 \mathrm{mg} /$ grains.

\subsubsection{Etrahydropalmatine Content Determination [10]}

The chromatographic conditions: C18 chromatographic column (Hypersil BDS, $4.6 \mathrm{~mm} \times 150 \mathrm{~mm}, 5 \mu \mathrm{m}$ ); The mobile phase was acetonitrile-0.1\% phosphoric acid solution (triethylamine adjust $\mathrm{pH}$ value to 6.0) (40:60); the velocity was $1 \mathrm{ml} \cdot \mathrm{min}^{-1}$; column temperature $35^{\circ} \mathrm{C}$; detection wavelength $280 \mathrm{~nm}$; sample quantity $10 \mu \mathrm{l}$.

The preparation of the reference substance solution: Precisely weigh the right amount of etrahydropalmatine, add methanol made each $1 \mathrm{ml}$ contains $75 \mu \mathrm{g}$ solution.

The preparation of test sample solution: Take the product of 2 g, precision said, try adding concentrated ammonia liquid-methanol (1:20) mixture $50 \mathrm{ml}$, water bath $50^{\circ} \mathrm{C}$ ultrasonic treatment for 20 minutes, the refrigerator placed $2 \mathrm{~h}$, filtration and the filtrate to dry residue add methanol solution, transferred to the 5 ml volumetric flask, and diluted to scale, shake well, filtration, take the filtrate.

Negative for preparation of test sample solution: Lack of Rhizoma Corydalis negative samples according to the preparation of test sample solution method, the reference solution.

Linear range: Precision separately according to the chromatographic conditions, the drain etrahydropalmatine solution $1,3,5,10,15,20 \mu \mathrm{l}$ sample, peak area as the ordinate, sample quantity as abscissa drawing standard 
curve, calculated the regression equation $\mathrm{Y}=792.36 \mathrm{X}-2.009\left(\mathrm{r}^{2}=1.0000\right)$, the result showed that etrahydropalmatine sample quantity is within the scope of 0.075 to $1.50 \mu \mathrm{g}$ good linear relationship with the peak area.

Specific test: Precision drain etrahydropalmatine, test samples, negative solution, according to the determination of the chromatographic conditions, the results of test samples of chromatographic peak of chromatographic peak of etrahydropalmatine and adjacent to the baseline separation of theoretical plate number calculated by etrahydropalmatine peak is not less than 3000 , degree of separation $>1.5$, negative without interference (see Figures 8-10).

Precision test: Draw the reference substance solution precision, determination of sample 6 times in a row, record chromatograph chart, determination of etrahydropalmatine peak area of each sample, the result etrahydropalmatine average peak area was 516.0 , RSD was $1.83 \%$, the results showed that the precision is good.

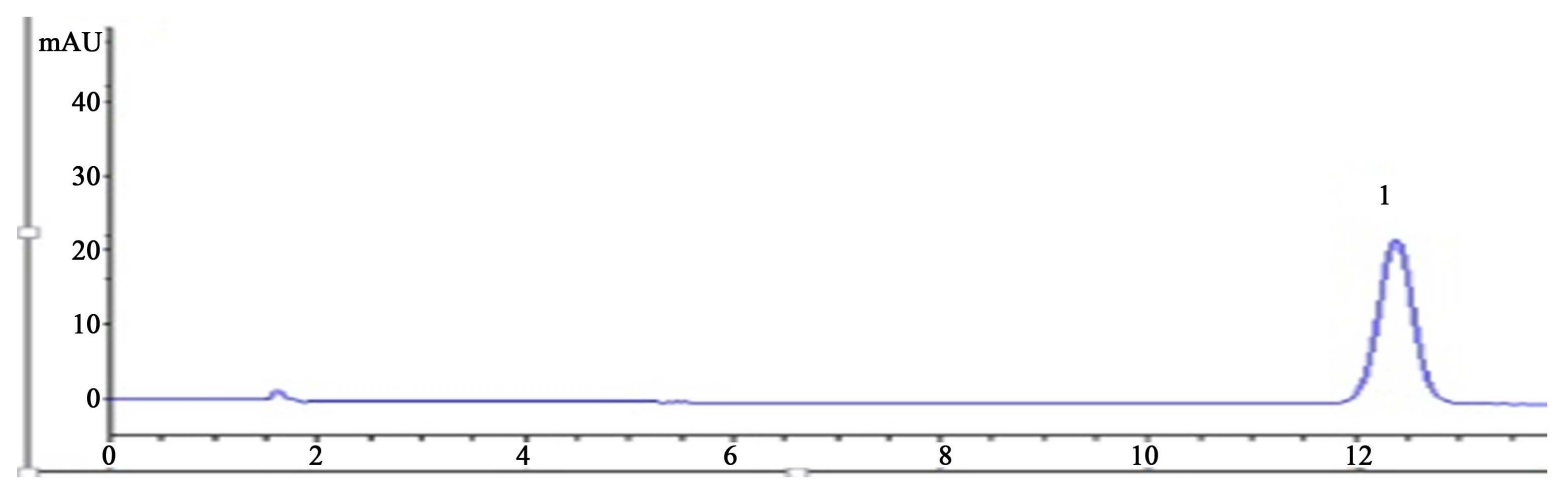

Figure 8. Etrahydropalmatine chromatogram. 1. The wave peak of Etrahydropalmatine.

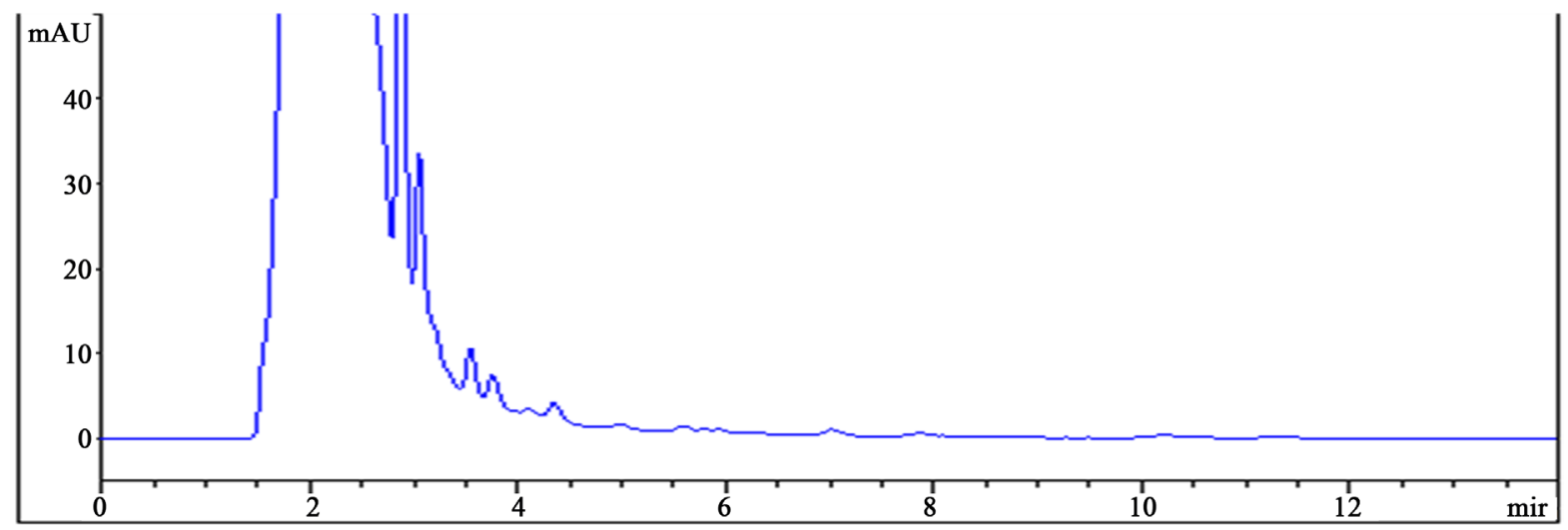

Figure 9. The suppository of Penyankang lack of Rhizoma Corydalis negative chromatograms.

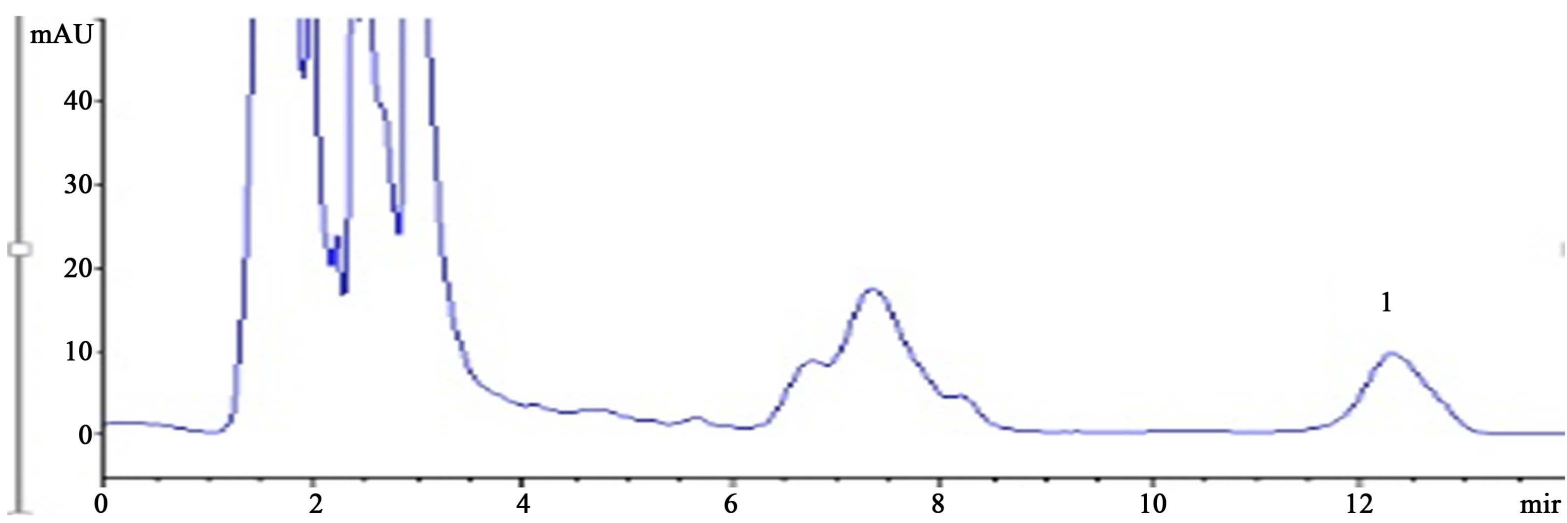

Figure 10. The suppository of Penyankang sample chromatograms. 1. The wave peak of Etrahydropalmatine. 
Stability test: Precision from the test solution, at $0,2,4,6,8,10 \mathrm{~h}$ sample, record each peak area of sample, the sample average peak area was 422.3 , RSD was $2.05 \%$, the results showed that within $10 \mathrm{~h}$ of test sample solution stability.

Repeatability test: Take 6samples, according to the preparation method of the preparation of test sample solution, determination of peak area according to the chromatographic conditions, the content and relative standard deviation calculation, the results of the content of etrahydropalmatine of the average was $0.097 \mathrm{mg} \cdot \mathrm{g}^{-1}$, RSD was $0.94 \%$, the results showed that the method has good repeatability.

Sample recovery rate test: Recycling method with adding samples, samples from known content $(0.097$ $\mathrm{mg} \cdot \mathrm{g}^{-1}$ ) about $1 \mathrm{~g}$, precision said, a total of $6,50 \mathrm{ml}$ volumetric flask, respectively, to join the preparation of the reference substance solution $2 \mathrm{ml}\left(0.049 \mathrm{mg} \cdot \mathrm{g}^{-1}\right)$, and solvent dilution and constant volume to scale. According to the preparation of test sample solution, chromatographic conditions were determined according to the above, the calculation of recovery, the result of etrahydropalmatine the average recovery was $98.74 \%$, RSD was $1.85 \%$, it showed that the method of sample recovery rate, better accuracy.

Determination of the sample: Take 3 batch of pilot samples, 2 per batch, according to the preparation methods of the preparation of sample solution of test sample solution, according to the determination of the chromatographic conditions, calculate the content of etrahydropalmatine. 3 batches of samples determination results to an average of $0.210 \mathrm{mg} /$ grain, according to the 2010 edition of "Chinese pharmacopoeia" a "Rhizoma Corydalis" relevant provision, under the provisional product containing tetrahydropalmatine total amount not less than $0.054 \mathrm{mg} / \mathrm{grains}$.

\section{Results}

TLC spots were clear and well separated without interference in the negative reference and the compounds showed a good linearity in a determination range. The method is simple, reliable and accurate with good precision. It can be used for the quality control of Penyankang Suppository.

\section{Discussion}

To better control the quality of the preparation, dandelion and dahurian Patrinia herb also has carried on the corresponding thin layer identification research, having tried various methods to deal with the sample, but the negative have interference, so giving up these two herbs thin layer identification in quality standards.

About the Content determination of salvianolic acid B, it examines the extraction solvent and extraction method of test sample solution. In the study of extraction solvent, the final effect was extracted by water, $25 \%$ methanol, $50 \%$ methanol were better, but water extract was easy to mildew, not easy to save; and $50 \%$ methanol extracted the suppository, cool off after the filter matrix was still within $2 \mathrm{~h}$ precipitation, after injecting liquid, easily blocked chromatographic column, the column pressure, so the final choice $25 \%$ methanol for salvianolic acid B content determination of extraction solvent. In the extraction method of investigation, investigated the water bath respectively, ultrasonic and reflux extraction methods. No difference between the three methods of extracting effect. After ultrasonic extraction of the sample solution was easy to filter, so the choice was the simple ultrasonic extraction method for content determination of extraction.

\section{References}

[1] Wang, C.-Y., Song, Y., Cao, L., et al. (2015) Optimization of Preparation Technology for Penyankang Suppositories. Chinese Journal of Experimental Traditional Medical Formulae, 21, 31-34.

[2] Zhang, Z.-W. (2007) Traditional Chinese Medicine Pharmacy. 4th Edition, China Press of Traditional Chinese Medicine Press, Beijing, 288-294.

[3] (2010) Chinese Pharmacopoeia. 19.

[4] Zheng, S., Pan, W.-D., Cao, P.-X., et al. (2010) Study of Quality Standard for Hushi’s Cool-Eczema Nebula of Guizhou Miao-Minority Medicine. Chinese Archives of Traditional Chinese Medicine, 3, 604-606.

[5] Li, Z.-G. (2007) Studies on the Identified Methods of Radix Salviae Miltiorrhizae and Establishment of the Control TLC Fingerprint. Chinese Pharmaceutical Affairs, 21, 1006-1007.

[6] An, R., Zhou, S.-L., You, L.-S., et al. (2008) Quality Standard for Compound Shenyi Granule. Chinese Traditional Patent Medicine, 30, 1781-1785. 
[7] Sun, A.-P., Xie, X.-M. and Zhou, J. (2008) Identification of Rhizoma Corydalis by Thin-Layer Chromatography. Anhui Medical and Pharmaceutical Journal, 12, 224-225.

[8] Zhang, X.-H., Mao, C.-Q., Lu, T.-L., et al. (2010) Study on Quality Standard of Sparganiumstoleniferum. Lishizhen Medicine and Materia Medica Research, 21, 1384-1385.

[9] Xue, J., Ye, Z.-L., Li, D.-K., et al. (2013) Simultaneous Determination of Salvianolic Acid D, Rosmarinic Acid, Lithospermic Acid and Salvianolic Acid B in the Salvianolic Acid Extract by HPLC. Chinese Journal of Experimental Traditional Medical Formulae, 19, 70-73.

[10] Su, J., Wang, B.-Q. and Lin, R.-C. (2010) Herbs Containing Ingredients of Tetrahydropalmatine and Research Progress on Preparation Content Determination Method. Chinese Journal of Information on Traditional Chinese Medicine, 17, $110-112$.

Submit or recommend next manuscript to OALib Journal and we will provide best service for you:

- Publication frequency: Monthly

- 9 subject areas of science, technology and medicine

- Fair and rigorous peer-review system

- Fast publication process

- Article promotion in various social networking sites (LinkedIn, Facebook, Twitter, etc.)

- Maximum dissemination of your research work

Submit Your Paper Online: Click Here to Submit

Contact Us: service@oalib.com 